\title{
Reproductive ecology of buzz-pollinated Ouratea spectabilis trees (Ochnaceae) in Brazilian Cerrados
}

\author{
D. Montesinos ${ }^{1}$ and P. Oliveira ${ }^{2}$ \\ ${ }^{1}$ Centre for Functional Ecology, DCV-FCTUC, Universidade de Coimbra, Calçada Martim de Freitas, \\ 3000-456 - Coimbra, Portugal \\ ${ }^{2}$ Universidade Federal de Uberlândia, Av. Pará 1720, Campus Umuarama, Caixa postal 593, \\ 38400-902 - Uberlândia, Minas Gerais, Brazil \\ Correspondence to: D. Montesinos (danimontesinos@gmail.com)
}

Received: 4 October 2014 - Revised: 26 November 2014 - Accepted: 1 December 2014 - Published: 14 January 2015

\begin{abstract}
Ouratea spectabilis is a ubiquitous tree species in the Brazilian savannas, or Cerrados, where it plays an important ecological role. We studied its anthesis phenology, pollination biology, pollen viability, and pollen tube growth, and executed a set of intra- and interspecific experimental crosses to determine its mechanisms of incompatibility and reproductive ecology. The species presents a specialized buzz pollination syndrome and is served by a small array of specialized pollinator species. It is a mostly self-incompatible species, and although self-pollination is possible, it strongly reduces fertility, with reproductive outputs for hand self-pollination similar to those of interspecific crosses with the co-generic species $O$. hexasperma. Incompatibility with another commonly co-occurring co-generic species, $O$. floribunda, was complete, with a null fruit set, as occurred for the autonomous apomixis tests. Our pollen tube growth observations indicate that incompatibility occurs at the style, and is thus pre-zygotic. All three Ouratea species presented very high pollen viability. Manual pollen supplementation did not increase seed sets. Nevertheless, even after excess manual pollen supplementation, seed-to-ovule ratios were only $30 \%$. Such limits are common in stressful environments, and fruit production for most Cerrado species is reported to be regularly under those levels. The apparent ubiquity of this fertility limit among Cerrado species poses interesting ecological questions, such as the role of environmental stress on reproduction and the potential overproduction of ovules as an evolutionary strategy to deal with seed predation - questions which deserve further research in the future.
\end{abstract}

\section{Introduction}

Reproduction is an essential component of fitness and thus is subjected to strong selective forces. The development of specialized pollination syndromes, the delimitation of reproductive barriers, and the determination of the limits to fertility provide essential clues about the relative importance of the selective forces acting over a species. In this work we aim to understand the reproductive ecology of an important tree species of the Brazilian savannas, or Cerrados. "Cerrado" is the local name given to neotropical savanna areas in central Brazil. A marked dry season, nutrient-poor soils, and periodic fires have been considered the determinants of this vegetation type (Oliveira and Marquis, 2002). It is the secondmost important vegetation type in Brazil, after the Amazon rain forests, and covers approximately one-fifth of Brazilian territory. Its flora is very rich, comprising more than 800 species of trees, with perhaps 4 times that number of herbs and shrubby species (Oliveira and Gibbs, 2000); however the few studies on reproductive biology of savanna communities have covered less than $10 \%$ of the species (Oliveira and Gibbs, 2002). Those savannah areas are characterized by a high beta diversity of plant species with a turnover of species from area to area (Bridgewaters et al., 2004).

Several species of Ouratea (Ochnaceae) are ubiquitous across Brazilian Cerrados (Ratter et al., 2003; Bridgewater et al., 2004). Nevertheless, few studies have been conducted about species of this genus (but see Barros-Henriques, 1999), as is the case for many Cerrado plant species. Phenological 
and reproductive data are fundamental in order to understand persistency and distribution of the plants (Rathcke and Lacey, 1985; Munguía-Rosas et al., 2011), and are particularly important in tropical environments, where seasonal variations do not limit phenological and reproductive processes as much as they do in temperate environments (Frankie et al., 1974; Munguía-Rosas et al., 2011). Significantly, Ouratea species, including Ouratea spectabilis, present specialized poricidal anthers which only release pollen when pollinators vibrate at a determined frequency. This pollination type, also known as buzz pollination, is a very specialized pollination syndrome intended to reduce pollen loss to inefficient pollinators and, thus, to increase pollination specificity and efficiency (Faegri and van der Pijl, 1979; Percival, 1979; DeLuca and Vallejo-Marín, 2013). Typically, in buzz pollination, pollinators are rewarded by pollen and not by nectar, and only a small group of specialized visitors are able to vibrate their wings in the appropriate frequency and then collect the pollen (Buchman and Buchman, 1981; Buchman, 1983). Buzz pollination is present in up to 20000 plant species across the world, and has evolved independently many times, occurring in species from up to 65 families, including the agriculturally important Solanaceae family (De Luca and Vallejo-Marín, 2013).

In this study we aim to describe $O$. spectabilis anthesis phenology and pollination ecology, and to experimentally study the intra- and interspecific reproductive barriers and mechanisms of incompatibility by controlled intraspecific crosses, self-pollination, and apomixis in O. spectabilis and also through interspecific crosses with the close co-generic species $O$. hexasperma and $O$. floribunda. This information is essential to understand the auto-ecology of the species and to assess the ecological importance of buzz pollination in Cerrados.

\section{Materials and methods}

\subsection{Study species}

Ouratea spectabilis (Mart.) Engl. or folha-de-serra; O. hexasperma (St. Hill.) Benth. or vassoura de bruxa; and O. floribunda Engl. or batiputá are three closely related shrubs or trees from the Ochnaceae family. They frequently co-occur in Brazilian Cerrado habitats. Trees are deciduous and typically reach up to 4-5 m. All three species flower from $\mathrm{Au}-$ gust to September, and fruits ripen from October to November. Flowers are hermaphrodite, yellow, and without nectar. Extra-floral nectaries are known to be critical in a number of interactions with different species of ants and $O$. spectabilis (Byk and Del-Claro, 2010). However, pollinators are apparently rewarded exclusively in the form of pollen, which is produced by poricidal dehiscent anthers.

\subsection{Study site}

Fieldwork was carried out between July and September 2001 in the Cerrado reserve (640 ha) of the Clube de Caça e Pesca Itororó, Uberlândia, State of Minas Gerais, Brazil (18 $59^{\circ} \mathrm{S}$, $\left.48^{\circ} 18^{\prime} \mathrm{W}\right)$. The vegetation is a cerrado sensu stricto, consisting of a dense scrub of shrubs and trees with a fair amount of herbaceous plants (Oliveira and Marquis, 2002). A rainy and hot season occurs from September to April, and a dry and cold season from May to August (Oliveira and Marquis 2002). We selected six distant ( $>10 \mathrm{~m}$ ) individuals of $O$. spectabilis which were individually marked. Within each tree, more than 100 flowers $\left(N_{\text {total }}=634\right.$ flowers $)$ were bagged before the anthesis to exclude pollinators, and were subsequently used in the hand pollination experiments and to estimate fruit set from natural pollination.

\subsection{Flower phenology and pollen viability}

Flowers from each marked tree were marked in different stages of the anthesis. Characteristics of each stage and time to change from one stage to the next were recorded. Pollen viability was estimated from three stamens from three flowers of three different individuals of each of the three Ouratea species. Although only $O$. spectabilis was tested as a pollen receiver, the quantification of pollen viability allowed us to discard this factor as limiting for pollination success. For each stamen, the viability of 500 pollen grains was assessed by using the acetic carmine procedure, which allows distinguishing stainable cytoplasm of putatively viable pollen grains from empty non-viable grains (Radford et al., 1974). Generalized linear models with quasi-binomial distribution of errors were fit to the pollen germination data with $\mathrm{R}$ 3.1.2 (Ihaka and Gentleman, 1996) in order to test for differences in pollen viability among the three studied species. Plant species was used as a fixed factor, and each individual sample, from each of three different trees for each species, as a replicate. We considered each germinated pollen grain as a positive count within the total number of grains observed (500 per sample) by using the command cbind in $\mathrm{glm}$.

\subsection{Pollination ecology}

Insects visiting flowers at the marked trees were observed at the peak of the flowering season (August 2001), on two different sunny days, for a total of $21 \mathrm{~h}$. Number of flowers visited and time spent in each flower were recorded. Individuals from each visitor species were collected and taxonomically determined to the genus level. General linear models were performed in SPSS 19.0 (IBM, 2010) in order to find differences among average time per flower spent by each particular pollinator species. 
Table 1. Number of $O$. spectabilis flowers visited by each pollinator species and average time per visit (mean \pm SD). Different letters indicate statistically significant differences $(p \leq 0.05)$ for flower visitation times.

\begin{tabular}{lll}
\hline $\begin{array}{l}\text { Pollinator } \\
\text { species }\end{array}$ & $\begin{array}{l}\text { Number of flowers } \\
\text { visited }\end{array}$ & $\begin{array}{l}\text { Average time per } \\
\text { flower (seconds) }\end{array}$ \\
\hline Centris sp. 1 & 245 & $2.88 \pm 0.75^{\mathrm{a}}$ \\
Centris sp. 2 & 123 & $3.19 \pm 0.80^{\mathrm{b}}$ \\
Apis mellifera & 40 & $4.02 \pm 2.20^{\mathrm{c}}$ \\
\hline
\end{tabular}

\subsection{Pollination treatments}

Eight different pollination treatments were applied to a total of 1077 flowers from six different individual trees in order to study the reproductive system of $O$. spectabilis. Pollen exclusion bags of nylon mesh were set on a total of 634 flowers before the anthesis to prevent insect pollination; we also left untouched a large number of flowers from each individual as controls for natural pollination. In order to avoid self-pollination, some of the flowers were emasculated before stigmas were receptive. Pollen was extracted from the poricidal anthers by vibrating stamens with a diapason and collecting expulsed pollen in a microscope plate. Flower stigmas were rubbed to plates in order to pollinate them. Flowers were bagged again after the treatment until fruits were formed and counted.

Pollination treatments were (a) controls: composed by a large number of flowers marked and simply left without any treatment; (b) intraspecific cross-pollination (not emasculated): flowers were pollinated with pollen from other individuals in the population of the same species; (c) intraspecific cross-pollination (emasculated): flowers had the same treatment as $b$ but were manually emasculated before anthers were ripe (this group served as a control of the effect of the emasculation treatment); (d) spontaneous selfpollination: flowers were left inside pollen exclusion bags without further treatment; (e) hand self-pollination: flowers were pollinated with pollen from a different flower from the same tree; ( $f$ and $g$ ) interspecific pollination: flowers were emasculated before stigmas were receptive, and were later pollinated with pollen either from $O$. hexasperma or $O$. floribunda from the same location; and (h) apomixis: flowers were emasculated and kept inside pollen exclusion bags to test for autonomous apomixis.

When the fruits developed, the number of mature carpels from each treated flower was counted in order to calculate seed sets obtained for each treatment. This rate was calculated as the number of mature carpels observed, divided by the number of flowers treated, multiplied by 5 , which was the number of carpels usually present in $O$. spectabilis fruits. Generalized linear models with quasi-binomial distribution of errors were fit to the data with R 3.1.2 in order to test for differences among pollination treatments. Pollination treat- ment was used as a fixed factor, and each individual tree as a replicate. We considered each observed seed (carpel) as a positive count within the maximum number of ovules available in the marked flowers (five ovules per flower) by using the command cbind in glm. Unfortunately, we did not record how many carpels per flower within each tree were observed.

Finally, we calculated an index of self-incompatibility (ISI; sensu Bullock, 1985) in order to define the breeding system. This index ranges from 0 to 1 and is the ratio between self- and cross-pollination fertility, where 0.25 has been considered the upper limit for self-incompatible species. The reproductive efficacy index (REI; sensu Ruiz and Arroyo, 1978) is the ratio between seed set from open pollinated and cross-pollinated flowers; it also ranges from 0 to 1 and is used to estimate the relative efficacy of natural pollination.

\subsection{Pollen tube growth}

Pollen germination and growth were studied using fluorescence microscopy with aniline blue stain (adapted from Martin, 1959). Four to 16 flowers per treatment were marked before the anthesis and bagged to exclude pollinators. Half of the flowers were collected $24 \mathrm{~h}$ after either hand self- or cross-pollinations, and the other half of the flowers were collected $48 \mathrm{~h}$ after hand pollination treatments. Treatments were the same as described for the estimation of fruit sets.

\section{Results}

\subsection{Flower phenology}

We successfully characterized six different stages of the flower development of $O$. spectabilis: Immature flowers (1) were characterized by small green buds, with calix equal in size to corolla - this stage lasted 7 days; (2) Calix remained similar in size with the corolla, but petal color starts to change to yellow - this stage lasted from 3 to 11 days; (3) corolla was already bigger than chalice and buds turned yellow, and stamens started to open from this point on - this stage will last only 1 day; (4) anthesis began when flowers started to open and was completely developed with stigmas receptive - this stage lasted 2 days; (5) petals fell, but stamens remain in the flower for 2 more days; and (6) no petals, sepals, or stamens left, and fruit development started.

\subsection{Pollen viability}

Pollen viability estimates were high for all three species, averaging $99.97 \pm 0.03 \%$ of viable pollen grains for all three species, which did not differ in their pollen viability rates $(t=-0.772, d f=8, p=0.469, t$ value derived from the division of the estimates by the standard error). This indicates that our subsequent fertility results for the different pollination treatments were not limited by pollen viability. 
Table 2. Total number of $O$. spectabilis flowers used on each treatment, and number of fruits (and percentage) and carpels observed as a result of each treatment.

\begin{tabular}{lccc}
\hline Treatment & N of flowers & N of fruits (\%) & N of carpels \\
\hline Control & 443 & $196(44.2)$ & 438 \\
Intraspecific (not emascul.) & 71 & $35(49.3)$ & 105 \\
Intraspecific (emasculated) & 26 & $5(19.2)$ & 16 \\
Self-spontaneous & 288 & $25(8.7)$ & 57 \\
Self-manual & 66 & $3(4.5)$ & 8 \\
Interspecific O. hexasperma & 28 & $1(3.6)$ & 4 \\
Interspecific O. floribunda & 25 & $0(0)$ & 0 \\
Apomixis & 130 & $0(0)$ & 0 \\
\hline
\end{tabular}

Table 3. Observed number of flowers with pollen and/or pollination tubes ending in that point of the feminine structures for each pollination treatment.

\begin{tabular}{lcccc}
\hline O. spectabilis & Stigma & In the style & End of the style & Total \\
\hline Self-pollination & 1 & 1 & 3 & 5 \\
Intraspecific & 7 & 2 & 9 & 18 \\
Inter-sp. O. hexasperma & 4 & 3 & 0 & 7 \\
Interspecific O. floribunda & 1 & 3 & 0 & 4 \\
\hline O. hexasperma & Stigma & In the style & End of the style & Total \\
\hline Self-pollination & 0 & 1 & 3 & 4 \\
Intraspecific & 1 & 1 & 4 & 6 \\
Interspecific O. spectabilis & 4 & 0 & 0 & 4 \\
Interspecific O. floribunda & 2 & 1 & 1 & 4 \\
\hline
\end{tabular}

\subsection{Pollination ecology}

Ouratea spectabilis experienced a high number of flower visits, although trees were visited only by three bee pollinator species. Those bees visited a total of 408 flowers during the $21 \mathrm{~h}$ of observations. Only the two Centris species vibrated their wings to liberate pollen. Apis mellifera bees did not vibrate the flowers, and their activity was limited to collect pollen spilled by previous visitors, spending the largest time per flower among the three observed species. Significant differences were found in the average time spent per flower for each species $\left(F_{1,2}=23.6, p<0.001\right)$. Centris sp. 1 spent significantly less time per flower than the other two visitors (post hoc $p=0.001$ and $p=0.007$ ) and was by far the most common pollinator, while Centris sp. 2 presented marginally significant pollination visitation rate differences than Apis mellifera $(p=0.068$; Table 1). Centris pollinators stand hung on the stamens and vibrated their wings in order to liberate pollen from the poricidal anthers (buzz pollination or sonication). Pollen was deposited on the ventral side of the insects' thorax, abdomen, and legs. Contact of the pollinator body with the stigmas of flowers visited subsequently resulted in pollination. Each fruit bore up to five (O. spectabilis, O. floribunda) or six seeds (O. hexasperma), from five or six carpels, so seed set can be easily determined.

\subsection{Pollination treatments}

Pollination success varied greatly between treatments in $O$. spectabilis. Percentage of fertility, as the proportion of mature carpels over the total carpels pollinated, is shown in Table 2. Statistical analysis showed significant differences between several pollination treatments. Controls and non-emasculated intraspecific crosses resulted in high but significantly different fertility rates $(t=-2.153 ; d f=39$; $p=0.039)$, while emasculated intraspecific crosses presented a slightly lower and also statistically significant reduction in fertility $(t=-4.180 ; d f=39 ; p \leq 0.001)$. However, the main difference was observed between these three successful kinds of crosses and the rest of the treatments, which resulted in very low fertilities $(t=-0.008 ; d f=39$; $p=0.994$; Table 3 and Fig. 1). Emasculation treatments did have a somewhat negative effect on fruit sets, but this group still presented high fertility values. In the low fertility group two treatments, the apomixes and interspecific crosses with $O$. floribunda, gave a rotund zero, indicating both that $O$. hexasperma does not present apomixis and that the species is extremely incompatible with $O$. floribunda. Interspecific crosses with $O$. hexasperma resulted in very low seed sets, but not as low as the ones with the other species, indicating a weakest reproductive barrier with this species. 
Index of self-incompatibility, calculated as the division of the average self-pollination value (spontaneous and manual) and the average cross-pollination value (emasculated and not emasculated), was 0.15 , indicating that $O$. spectabilis is clearly a self-incompatible species.

Reproductive efficacy index, resulting from the division of the controls' value by the average cross-pollination value, was 0.94 , indicating an extremely high efficacy for the natural pollination mechanism.

\subsection{Pollen tube growth}

Differentiation of pollen tubes on microscope preparations was difficult both for $O$. spectabilis and for $O$. hexasperma. Callose fluorescence was mostly weak. For both species, self-pollination treatments and intraspecific crosspollinations allowed for the observation of tube growth down the end of the style. In contrast, interspecific crosses showed tube growth arrested at the beginning or middle of the style, indicating that interspecific incompatibility mechanisms are likely pre-zygotic (Table 3 ).

\section{Discussion}

Ouratea spectabilis trees showed strong reproductive barriers to self-pollination and can be classified as self-incompatible trees, presenting an index of selfincompatibility (Bullock, 1985) of 0.15, well below the commonly agreed limit of 0.25 for self-incompatible species. Self-pollination is nonetheless possible, but strongly penalized in terms of fertility, with self-pollinated flowers presenting seed sets as low as the ones obtained for interspecific crosses with $O$. hexasperma. They are closely related species which seem to present a strong but incomplete reproductive barrier. Incompatibility with the other co-occurring cogeneric species $O$. floribunda is complete, and no carpel developed into fruit after experimental crosses, a level of fertility similar to that of apomixes treatment, which was also null. Pollen tube growth observations strongly pointed towards the existence of a pre-zygotic reproductive barrier, since pollen tube growth was arrested at the style for incompatible treatments.

We did not observe any activity of pollen-eater insects, i.e., those that "rob" pollen without providing any pollination service. Pollen eaters seem to be uncommon for the genus, and previous studies (Barros-Henriques, 1999) noticed only two inflorescences attacked by this kind of insect in the closely related $O$. hexasperma. However, that same study found a $70 \%$ pollen viability for $O$. hexasperma, while our estimations of pollen viability neared $100 \%$ for the three studied species. Given the simplicity of the methodology, it is plausible to think that differences were due to environmental or regional conditions, and that pollen viability was not a limiting factor in either study, but that it can potentially experience important regional and temporal variability.

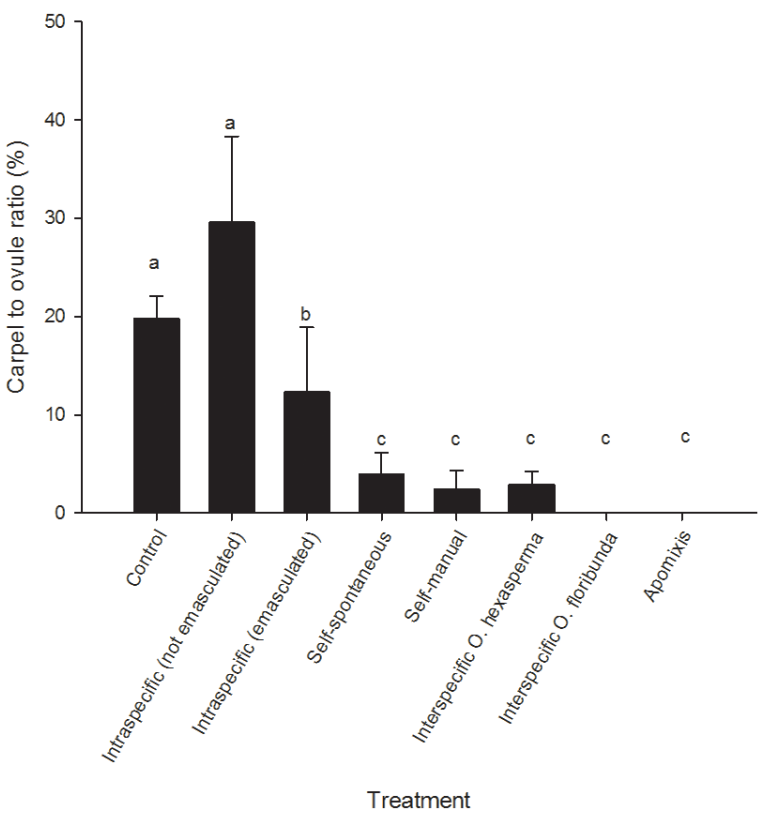

Figure 1. Carpel-to-ovule ratio for each of the treatments in $O$. spectabilis flowers, calculated as the \% of the ratio between the number of mature carpels developed per total number of ovules available. Mean $\pm \mathrm{SE}$ is shown. Different letters indicate statistically significant differences $(p \leq 0.05)$.

Pollinators continuously visited $O$. spectabilis trees throughout the day and among days. As expected for the extremely specialized buzz-pollinated flowers, the array of pollinators visiting them was small, resulting in a remarkably high REI of 0.95 (in a 0-1 range; Ruiz and Arroyo, 1978). Such specialization is consistent with the high beta diversity characteristic of Cerrados (Bridgewaters et al., 2004). Although pollen supplementation resulted in a slightly higher seed set, maximum fertility was still under $30 \%$, suggesting that some pollen limitation might be present but that other factors could be playing a more important role in limiting tree fertility. We hypothesize that water or nutrient limitation, or even a physiological mechanism anticipating such limitation in the future, could be playing a role in setting a maximum investment in reproduction. Similar fertility levels are common for Cerrado species, and most of the species for which fertility studies have been performed show seed-to-ovule ratios below $30 \%$ (Barbosa, 1983; Barros, 1992; Oliveira et al., 1992; Oliverira and Gibbs, 1994; Oliveira and Sazima, 1990; Proença et al., 1994). Ecological theory also suggests that ovule overproduction could be a mechanism to control for pre-dispersal seed predation when associated with early abortion of preyed ovules (Obeso, 2002; Montesinos et al., 2010). In any case, this apparent waste of resources in producing ovules which are unlikely to become seeds poses interesting ecological and evolutionary questions with broad implications for the understanding of Cerrado dynamics, and it deserves further attention in future research. 
Author contributions. D. Montesinos executed fieldwork and led the analyses of data and the writing of the manuscript. P. Oliveira conceived and designed the study and collaborated on the analyses of data and on the writing of the manuscript.

Acknowledgements. The authors want to thank Christian Westerkamp for his help determining pollinator species, and to William Zaca for his help with fieldwork. Thanks go to Asociación Española de Cooperación Internacional (AECI) for an Intercampus scholarship to D. Montesinos (AECI-2001-115).

Edited by: J. Stadler

\section{References}

Barbosa, A. A. A.: Aspectos da ecologia reprodutiva de três espécies de Qualea (Vochysiaceae) num cerrado de Brasília, DF, Brasília, UnB, Disertação de Mestrado, 1983.

Barros, M. A. G.: Fenologia da floração, estratégias reprodutivas e polinização de espécies simpãtricas de Byrsonima Rich (Malpighiaceae), Rev. Brasil. Biol., 52, 343-353, 1992.

Barros Henriques, R. P.: Ecologia da polinização de Ouratea hexasperma (St. Hil.) Bail (Ochnaceae) em cerrado no Brasil central, Brasília, 4, 46-64, 1999.

Bridgewater, S., Ratter, J. A., and Ribeiro, J. F.: Biogeographic patterns, b-diversity and dominance in the cerrado biome of Brazil, Biodiv. Conserv., 13, 2295-2318, 2004.

Buchmann, S. L.: Buzz pollination in angiosperms, edited by: Jones, C. E. and Little, R. J., Handbook of experimental pollination biology, Van Nostrand Reinhold, New York, 73-113, 1983.

Buchmann, S. L. and Buchmann, M. D.: Autoecology of Mourini myrtiloides (Melastomatacea, Memecylae), an oil flower in Panama, Biotropica 13, 7-24, 1981.

Bullock, S. H.: Breeding systems in the flora of a tropical deciduous forest, Biotropica, 17, 287-301, 1985.

Byk, J. and Del-Claro, K.: Nectar- and pollen-gathering Cephalotes ants provide no protection against herbivory: a new manipulative experiment to test ant protective capabilities, Acta Ethol., 13, 3338, 2010.

De Luca, P. A. and Vallejo-Marín, M.: What's the "buzz" about? The ecology and evolutionary significance of buzz-pollination, Current Op. Plant Biol., 16, 429-435, 2013.

Faegri, K. and van der Pijl, L.: The principles of pollination ecology, Pergamon Press, New York, 244 pp., 1979.

Frankie, G. W., Baker, H. G., and Opler, P. A.: Tropical plant phenology: applications for studies in community ecology, edited by: Lieth, H., Phenology and seasonality modelling, SpringerVerlag, Berlin, 287-296, 1974.

IBM: SPSS Statistics for Windows, Armonk, NY, IBM Corp, 2010.
Ihaka, R. and Gentleman, R.: a language for data analysis and graphics, J. Comp. Graph. Stat., 5, 299-314, 1996.

Martin, F. N.: Staining and observing pollen tubes in the style by means of fluorescence, Stain Technol., 34, 125-128, 1959.

Munguía-Rosas, M. A., Ollerton, J., Parra-Tabla, V., and De-Nova, J. A.: Meta-analysis of phenotypic selection on flowering phenology suggests that early flowering plants are favoured, Ecol. Lett., 14, 511-521, 2011.

Montesinos, D., Verdú, M., and García-Fayos, P.: Relictual distribution reaches the top: Elevation constrains fertility and leaf longevity of the mountain tree Juniperus thurifera, Acta Oecol., 36, 120-125, 2010.

Obeso, J. R.: The costs of reproduction in plants, New Phytol., 155, 321-348, 2002.

Oliveira, P. E.: Reproductive biology of two species of Kielmeyera (Guttiferae) in the cerrados of Central Brazil, J. Tro. Ecol., 9, 67-79, 1993.

Oliveira, P. E.: Reproductive biology of woody plants in a cerrado community of Central Brazil. Flora, 195, 311-329, 2000.

Oliveira, P. E. and Gibbs, P. E.: Pollination biology and breeding systems of six Vochysia species (Vochysiaceae) in Central Brazil, J. Trop. Ecol., 10, 509-522, 1994.

Oliveira, P. and Marquis, R. J.: The cerrados of Brazil : ecology and natural history of a neotropical savanna, New York, Columbia University Press, 398 pp., 2002.

Oliveira, P. E. and Sazima, M.: Pollination biology of two species of Kelmeyera (Guttiferae) from Brazilian cerrados vegetation, Plant Syst. Evol., 172, 35-49, 1990.

Oliveira, P. E. and Gibbs, P. E.: Pollination and reproductive biology in cerrado plant communities, In: The Cerrados of Brazil. Ecology and natural history of a tropical Savanna, edited by: Oliveira, P. and Marquis, R. J., 424, New York, Columbia University Press, 329-349, 2002.

Oliveira, P. E., Gibbs, P. E., Barbosa, A. A., and Talavera, S.: Contrasting breeding systems in two Eriotheca (Bombacaceae) species of the Brazilian cerrados, Plant Syst. Evol., 179, 207219, 1992.

Percival, M.: Floral Biology, Pergamon Press, Oxford, 243 pp., 1979.

Proença, C. E. B. and Gibbs, P. E.: Reproductive biology of eight sympatric Myrtaceae from central Brazil, New Phytology, 126, 343-354, 1994.

Radford, A. E., Dickson, W. C., Massey, J., and Bell, C. R.: Vascular plant systematics, Harper and Row, New York, 891 pp., 1974.

Rathcke, B. and Lacey, E. P.: Phenological patterns of terrestrial plants, Ann. Rev. Ecol. Syst., 16, 179-214, 1985.

Ratter, J. A., Bridgewater, S., Ribeiro, J. F.: Analysis of the floristic composition of the Brazilian cerrado vegetation III: Comparison of the woody vegetation of 376 areas, Edinburgh J. Bot., 60, 57109, 2003.

Ruiz, T. Z. and Arroyo, M. T. K.: Plant reproductive ecology of a secondary deciduous tropical forest, Biotropica, 10, 221-230, 1978. 